\title{
Use of temporal and spatial information in estimating event completion time
}

\author{
STEPHEN K. REED and BOB HOFFMAN \\ San Diego State University, San Diego, California
}

\begin{abstract}
In this research, we investigated how students use temporal and spatial information to estimate the time to fill a tank. In Experiment 1, we evaluated the usefulness of a digital clock to calibrate temporal information and of an overflow tank to calibrate spatial information and investigated how component skills, such as judging volume, judging time, and performing mental calculations, correlate with estimation accuracy. In Experiment 2, we compared the usefulness of static and animated displays in order to test the prediction that static displays would be more useful when the fill rate remained constant but animated displays would be more useful when the fill rate changed. The findings, when combined with verbal reports, provide evidence regarding the use of four strategies that differ in their perceptual and arithmetic demands.
\end{abstract}

Estimating the time it will take for an event to finish occurs in various forms in our daily lives. For example, children on long car trips frequently ask their parents, "When are we going to be there?" The first author of this article prevented the repeated asking of this question by replying with an exact answer (such as 4:10 p.m.) the first time it was asked. He mentally calculated the answer by dividing the estimated remaining distance by the estimated average speed and added this time plus estimated stopping time to the current time. He became an expert at doing this and usually could accurately predict the estimated arrival time within several minutes (sometimes slightly varying the speed at the end of the trip to improve his accuracy).

Estimating event completion time typically depends on both perceptual and arithmetic skills, as can be illustrated with an example that is familiar to many of us in California. Imagine that you began filling a hot tub $20 \mathrm{~min}$ ago, returned, glanced at the tub, and saw that it was $80 \%$ full. You could then mentally solve the problem: If it takes 20 min to fill 0.8 tubs, how long will it take to fill 1 tub? A successful estimate depends on both an accurate perceptual judgment (the tank is $80 \%$ full) and an accurate solution of a proportional reasoning problem.

The purpose of the two experiments described in this study was to investigate the perceptual and arithmetic

Partial support for this work was provided by the National Science Foundation's Course, Curriculum and Laboratory Improvement Program under Grant DUE-9950746 (an animation-based tutor for algebra word problems). Any opinions, findings, and conclusions or recommendations expressed in this material are those of the author(s) and do not necessarily reflect the views of the National Science Foundation. The project Web site, including demonstrations and experiments, can be accessed at http://www.sci.sdsu.edu/mathtutor/. We thank Phillip Ackerman, Nancy Cooke, Timothy Hubbard, Gabriel Radvansky, Dan Schwartz, and anonymous reviewers for their helpful comments on previous versions of this article. Correspondence concerning this article should be addressed to S. K. Reed, CRMSE, 6475 Alvarado Road, Suite 206, San Diego, CA 92120 (e-mail: sreed@ sunstroke.sdsu.edu). strategies that people use to estimate event completion time. We investigated the use of four strategies that differ in their perceptual and arithmetic demands. Our analysis was influenced by Hecht's (2000) proposal that the success of strategies related to event perception depends on situational variables that support accurate estimates. For example, if you returned too late and the tub was overflowing, estimating how long it took to fill the tub would depend on how accurately you could estimate the amount of water that had overflowed. Other strategies might use temporal information, such as fill rate, rather than spatial information, such as volume. The choice of strategy could depend on which visual aids were available to calibrate time or volume.

We followed this approach in the present study by examining people's use of spatial and temporal information to estimate how long it would take two pipes to fill a tank. The participants in Experiment 1 viewed a 3-sec computer animation in which two pipes ran for $6 \mathrm{~h}$. On half of the trials, the tank was underfilled, and on half of the trials, the tank was overfilled at the end of the simulated $6 \mathrm{~h}$. The participants had to use this information to estimate how long it would take to fill 1 tank. We compared three strategies that differ in their use of the two visual aids (a digital clock and overflow tank), shown in Figure 1A. The digital clock ran from 0 to $6 \mathrm{~h}$ during some of the simulations and had the potential to help the students calibrate the rate of fill. The overflow tank also occurred on some of the simulations and had the potential to help the students calibrate the amount of overflow. Figure 1A shows both visual aids present, and Figure 1B shows both visual aids absent, for a simulation that filled 1.2 tanks.

The purpose of Experiment 1 was to compare three strategies that differed in their perceptual and arithmetic demands and in the potential usefulness of the two visual aids. In Experiment 2, we instructed the students to use a fourth (mental simulation) strategy in an attempt to com- 
pensate for the greater difficulty of events in which there was a change in the rate of fill. The situational variable in Experiment 2 was, therefore, whether the fill rate remained the same or changed as the tank was filled.

\section{Estimation Strategies}

Let us return to the example in which it took $20 \mathrm{~min}$ to fill 0.8 tanks. The problem can be solved by dividing the time ( $20 \mathrm{~min})$ by the proportion filled ( 0.8 tanks). The answer is $25 \mathrm{~min}$. We will refer to this strategy as a proportional volume strategy, because the proportion of the volume filled is used to judge the completion time. To use this strategy in the estimation task, it is necessary to both estimate the proportion of the tank filled and mentally calculate the answer.

The proportional volume strategy has several implications for how people would use the clock and the overflow tank in Figure 1A. First, the overflow tank should be very helpful when the tank overflows, because it should help calibrate the amount of overflow by providing an external display of volume. In contrast, the clock does not provide any useful information for the proportional volume strategy, because it provides an external display of time. In fact, animation does not provide any useful information for this strategy, because it is necessary only to know the proportion of liquid in the $\operatorname{tank}(\mathrm{s})$ after the simulation ends. A static image of this end state would be sufficient.

Table 1 summarizes the perceptual and arithmetic demands of the proportional volume strategy. The perceptual requirement is to estimate the amount of liquid, including the amount of overflow when it occurs. The arithmetic requirement is to divide the time by the proportion of the tank(s) filled. Students who use this strategy should be aided by an overflow tank on those trials in which the tank is overfilled.

The choice of strategies, as was suggested by Hecht's (2000) formulation, should depend on situational variables. For example, most hot tubs have seats, so the bottom half of the tub holds proportionally less volume than the top half of the tub. As a result, one can not assume that $80 \%$ of the total volume is filled when the water level reaches $80 \%$ of the height of the tub. The proportional volume strategy is difficult to use in this case, because of the difficulty of estimating the percentage of volume that has been filled.

An alternative strategy, which would be easier to use when the water has risen above the seats, is a temporal extrapolation strategy. Now imagine that you are filling a hot tub and decide that it will take 5 more minutes to fill, because you observe the water rising at a rate of 2 in. per minute and it needs to rise 10 more inches. Note that this decision requires explicit knowledge of the rate of fill, as determined by viewing a dynamic event. We label this strategy a temporal extrapolation strategy, because temporal information (fill rate) is used to infer how much more time is required to complete the task.

Table 1 shows that the perceptual demands of the temporal extrapolation strategy are to estimate the rate of fill and the unfilled volume. The arithmetic demands are to divide the unfilled volume by the rate of fill to calculate the additional time needed to fill the tank. Students who use this strategy should be aided by the clock on those trials in which the tank is underfilled, because the clock should help them estimate the rate of fill.

A third strategy, which we call a fill time strategy, is simply to check the clock when the tank is exactly full. The perceptual demands require attempting to coordinate the perception of two events, the changing clock time and the rise of water during the 3 -sec simulation. The rapid rate of fill may make this a difficult judgment, but an advantage of this strategy is that it does not require any computation. It does require a clock on overfill trials to record the time when the tank is exactly full.

\section{Identification of Strategies}

Kieras and Meyer (2000) have proposed that there are three requirements to build a model of human performance: (1) a specified architecture, (2) a representation of task strategies, and (3) a strategy identification methodology. Although we have not proposed a cognitive architecture, we have attempted to represent three different task strategies in terms of their perceptual and arithmetic demands (Table 1). Kieras and Meyer suggested that identifying task strategies is the stumbling block in building cognitive models. We propose three (hopefully converging) methods for identifying task strategies.
A

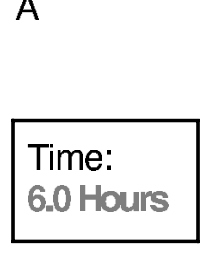

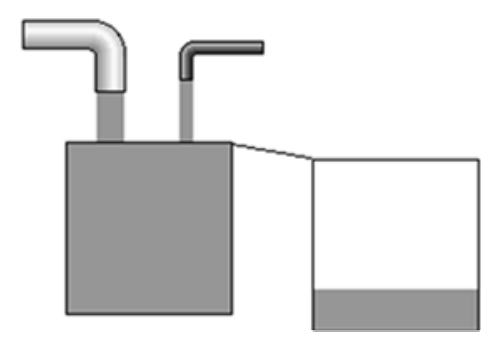

B

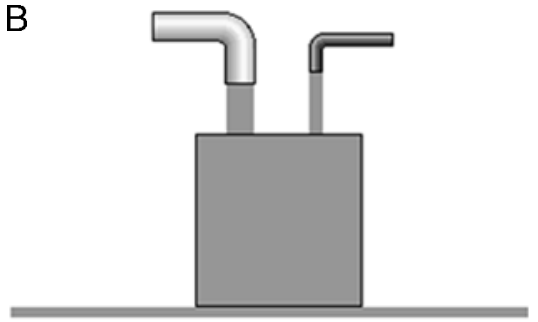

Figure 1. Example of a display showing 1.2 tanks filled for (A) the clock and tank condition and (B) the noaids condition. 
Table 1

Alternative Strategies for Estimating Event Completion Times

\begin{tabular}{llll}
\hline \multicolumn{1}{c}{ Strategy } & \multicolumn{1}{c}{ Perceptual Demands } & \multicolumn{1}{c}{ Arithmetic Demands } & Helpful Aids \\
\hline Proportional volume & $\begin{array}{l}\text { Estimate the proportion } \\
\text { of tank(s) filled including } \\
\text { the overflow tank }\end{array}$ & $\begin{array}{l}\text { Divide the time by the } \\
\text { proportion of tank(s) filled }\end{array}$ & $\begin{array}{l}\text { Overflow tank on } \\
\text { overfill problems }\end{array}$ \\
Temporal extrapolation & $\begin{array}{l}\text { Estimate the rate of fill } \\
\text { and the unfilled volume }\end{array}$ & $\begin{array}{l}\text { Divide unfilled volume by the } \\
\text { rate to determine additional } \\
\text { time required to fill the tank }\end{array}$ & $\begin{array}{l}\text { Clock on underfill } \\
\text { problems }\end{array}$ \\
Fill time & $\begin{array}{l}\text { Check clock for time } \\
\text { when tank is exactly full } \\
\text { Mentally simulate the } \\
\text { current fill rate until } \\
\text { the tank is full }\end{array}$ & $\begin{array}{l}\text { None } \\
\text { to the time to partially fill tank }\end{array}$ & $\begin{array}{l}\text { Clock on overfill } \\
\text { problems } \\
\text { problems }\end{array}$ \\
\hline
\end{tabular}

The first method exploits how visual aids relate to specific strategies. The clock and overflow tank provide calibration of time and volume, which should enhance performance, depending on which strategies are used. For example, a clock is required for the fill time strategy, so this strategy would predict a clock $\times$ fill interaction in which the presence of the clock improves performance on overfill problems but not on underfill problems. In contrast, a clock should help calibrate rate of fill for the temporal extrapolation strategy, so this strategy would predict that the presence of the clock should improve performance on underfill problems but not on overfill problems. The presence of the overflow tank should improve performance on overfill problems if people use the proportional volume strategy, because it provides calibration of volume. Note that if people used only the fill time strategy on overfill problems, the overfill tank would be irrelevant.

A second method for identifying strategies is verbal report. At the end of the estimation task, the students were asked to type a description of the strategy that they had used to make estimates. This method has the advantage of attempting to measure more specifically the strategies that individuals use.

A third method for identifying strategies is a correlational approach, in which the students performed three tasks that were components of the strategies. One task required them to estimate the volume of liquid in a tank, a second task required them to judge the time on the clock when a tank began to overflow, and a third task required them to estimate answers to proportional reasoning problems. This analysis measured how spatial, temporal, and arithmetic judgments correlated with performance on the estimation problems.

\section{EXPERIMENT 1}

Students saw an animation of how much of the tank(s) filled (varying from 0.5 to 1.5 tanks) after a simulated $6 \mathrm{~h}$ and had to estimate how long it would take to fill 1 tank. They were not allowed to use calculators or paper and pencil when making the estimates. The students were informed that a clock and an overflow tank would appear on some of the trials so we could determine whether these vi- sual aids were helpful. The dependent variable was estimation error, and the independent variables were fill (underfill or overfill), clock (present or absent), and overflow tank (present or absent). As is indicated in Table 1, interactions between tank and fill or between clock and fill provide evidence for the use of particular strategies.

Although the distinction between underfill and overfill is useful for predicting interactions with the two visual aids, it also allows us to predict a main effect of fill. There is evidence that people can occasionally use principles such as a range of values to constrain their estimates. For example, most students realize that mixing hot water and cold water will produce a mixture with a temperature that is between the temperatures of the two components (Dixon \& Moore, 1996; Reed \& Evans, 1987). The correct answers for filling the tank range from $12 \mathrm{~h}$ when 0.5 tanks are filled after $6 \mathrm{~h}$ to $4 \mathrm{~h}$ when 1.5 tanks are filled after $6 \mathrm{~h}$. The answers for the underfilled tanks are, therefore, between 12 and $6 \mathrm{~h}$ and the answers for the overfilled tanks are between 6 and $4 \mathrm{~h}$. The more restricted range for the overfilled tanks should enable students to produce more accurate estimates for these problems if they can use range to constrain their estimates.

\section{Method}

Participants. The participants were 58 undergraduates from introductory psychology classes. They received course credit for participating. They were tested in small groups in a computer lab containing iMac computers.

Stimuli. Each animation trial showed students how much of a $\operatorname{tank}(\mathrm{s})$ would be filled after $6 \mathrm{~h}$. There were 5 underfilled tanks $(0.5,0.6,0.7$, 0.8 , and 0.9 tanks) and 5 overfilled tanks $(1.1,1.2,1.3,1.4$, and 1.5 tanks). Each event began with an empty tank. The overfill tank (when present) began to fill immediately after the first tank was full on the overfill trials. After watching the tank(s) fill, the students estimated to the nearest one tenth of an hour how long it would take to fill 1 tank.

There were four experimental conditions determined by the presence or absence of the clock and overflow tank. The display contained both aids, only the clock, only the overflow tank, or neither aid. The students sat at a normal viewing distance from the computer screen and typed their estimates into a box below the tank.

The amount of time that the tank overflowed for a specific fill quantity was identical for the presence and the absence of the overflow tank. When there was no overflow tank, the liquid formed a puddle (the straight line shown in Figure 1B). The length of the line increased as the tank continued to overflow, but the area of the puddle was not identical to the area of the liquid in the overflow tank. The rationale for the pud- 
dle was that the amount of overflow would typically be difficult to judge in a real-life event. The overflow tank should, therefore, help calibrate the amount of overflow.

The clock ran from 0 to $6 \mathrm{~h}$ and showed the time to the nearest one tenth of an hour. It took $3 \mathrm{sec}$ to simulate the $6 \mathrm{~h}$, so the clock ran at a fast rate. It should be noted that the fill rate increased as the proportion of the tank(s) filled increased, because the simulated fill time was held constant at $6 \mathrm{~h}$. The rate of fill, therefore, varied by a factor of three, since the 3 -sec simulation would fill 0.5 tanks for the slowest rate and 1.5 tanks for the fastest rate.

Procedure. The students received 2 practice trials before beginning the 40 test trials. The first practice trial filled one third of a tank, and the students were informed that it would take $18 \mathrm{~h}$ to fill $1 \mathrm{tank}$. The second practice trial filled 1.67 tanks, and the participants were told it would take $3.6 \mathrm{~h}$ to fill one tank. The 40 problems ( 10 volumes $\times 4$ conditions) occurred in a different random order for each participant, under the constraint that the same fill quantity (such as 0.9 tanks) never occurred twice in a row. There was no feedback during the test trials. After completing the 40 test trials, the students were asked to type the strategy they had used to do the estimation task.

They then completed three component tasks that measured useful skills for producing accurate estimates. The first task showed them, in a random order, the 10 capacity conditions ranging from 0.5 to 1.5 tanks and asked them to judge the amount of liquid, with tanks as the unit of measurement (such as 0.7 tanks). The second task asked the students to estimate how long it would take to fill a tank for each of 10 verbal problems. The verbal problem stated how much of the tank(s) was filled (If it takes $6 \mathrm{~h}$ to fill 1.3 tanks, how long will it take to fill 1 tank?), so the students did not need to estimate volume from a visual display. The 10 problems, also presented in a random order, stated that it would take $6 \mathrm{~h}$ to fill each of the 10 capacities ( 0.5 to 1.5 tanks) used previously and, therefore, were verbal analogues of the simulation problems. The third task consisted of simulations of the 5 overflow problems and asked the students to use the clock to judge the time at which the tank began to overflow.

\section{Results}

Before discussing the results, we will present our rationale for handling outliers. Although the criteria selected for eliminating data are somewhat arbitrary, the criteria were selected without knowledge of how the cutoff values would influence the results. Our rationale is that large errors would unduly influence means, variances, and the parametric analyses of the data, such as in the use of analyses of variance (ANOVAs). We will later discuss the performance of the eliminated students to compare them with the better estimators.

In contrast, we included the data of all the participants when computing correlations with the component tasks by using Spearman rank order coefficients to reduce the influence of outliers. We included all the participants in the correlational analysis because (1) outliers are not a concern for us when nonparametric tests are used and (2) rejecting extreme scores would restrict the range and, possibly, reduce the correlation coefficients.

Estimation task. The amount of estimation error was determined for each participant and for each problem by taking the absolute value of the difference between the correct answer and the estimated answer. We then averaged the estimation errors for the five underfilled tanks and for the five overfilled tanks in each of the four experimental conditions. Table 2 shows the data. We excluded from analysis the results of any participant who produced an estimation error greater than $3 \mathrm{~h}$ for any of the eight
Table 2

Average Error (in Hours) in Estimating Event Completion Time

\begin{tabular}{lccccc}
\hline & \multicolumn{2}{c}{ Underfill } & & \multicolumn{2}{c}{ Overfill } \\
\cline { 2 - 3 } \cline { 5 - 6 } Visual Aids & $M$ & $S D$ & & $M$ & $S D$ \\
\hline Clock and tank & 0.74 & 0.56 & & 0.38 & 0.24 \\
Clock only & 0.74 & 0.50 & & 0.49 & 0.24 \\
Tank only & 0.78 & 0.58 & & 0.49 & 0.30 \\
No aids & 0.89 & 0.63 & & 0.64 & 0.24 \\
\hline
\end{tabular}

means shown in Table 2. The means were based on the data of 45 participants after 13 were excluded for exceeding this cutoff in at least one of the eight conditions (we will discuss the effect of excluding participants at the end of the Results section).

We analyzed the data in Table 2 in a three-factor, repeated measures ANOVA in which the three variables, were clock (present or absent), tank (present or absent), and fill (under or over). Each of the three main effects was significant. The presence of the clock reduced the average estimation error from 0.70 to $0.58 \mathrm{~h}[F(1,44)=5.61$, $\left.M S_{\mathrm{e}}=0.21, p<.03\right]$. The presence of the overflow tank reduced the average error from 0.69 to $0.59 \mathrm{~h}[F(1,44)=$ 7.48, $\left.M S_{\mathrm{e}}=0.11, p<.01\right]$. And as was predicted, the error on the overfilled tanks $(0.49 \mathrm{~h})$ was significantly less than the error on the underfilled tanks $[0.79 \mathrm{~h} ; F(1,44)=$ $\left.30.11, M S_{\mathrm{e}}=0.25, p<.001\right]$.

None of the interactions was significant, including the strategy-related interactions between clock and fill $\left[F(1,44)<1, M S_{\mathrm{e}}=0.19\right]$ and tank and fill $[F(1,44)=$ $\left.1.04, M S_{\mathrm{e}}=0.12\right]$. The lack of an interaction between tank and fill was surprising, because the proportional volume strategy should be aided by the overflow tank only when the tank overflows. The overflow tank reduced the error from 0.82 to $0.76 \mathrm{~h}$ for underfilled tanks and from 0.57 to $0.43 \mathrm{~h}$ for overfilled tanks. Although it is not clear how the overflow tank helped on underfill problems, this reduction in error was relatively small. The clock reduced the error from 0.84 to $0.74 \mathrm{~h}$ on underfilled tanks and from 0.56 to $0.42 \mathrm{~h}$ on overfilled tanks. The finding that the clock was useful for both underfilled and overfilled tanks suggests that there was some use of both the temporal extrapolation and the fill time strategies. This suggestion was confirmed by the reported strategies.

Reported strategies. Table 3 contains examples of reported strategies. We counted the number of reported strategies for which the use of the clock and/or the use of volume was explicitly mentioned as a basis for making judgments. The reported use of time and volume was approximately the same. Thirty-three of the 58 participants reported using the clock, and 39 of the participants reported using volume. This includes 18 participants who mentioned using both time and volume to make their estimates, as is illustrated in the following example:

When there was a time clock, I would watch that to see when it began to overflow. I also watched the time clock to see how much filled in the first hour to help estimate. The overflow tank helped me to know how much overflowed. 
Table 3

Examples of Categorized Strategies

Temporal Extrapolation Strategy

1. I used the timer as an aid to figure out the rate at which the tank filled and how fast the tank filled. The overflow diagram didn't help at all. If the water filled the tank quickly, I assumed it took less time than if it filled up slowly.

2. When the clock would appear on the screen I would try to estimate how much time was left and guess how much more time it would take to fill the container. If the clock was not present I would try to just guess by comparing the speeds of previous trials where there was a clock available.

\section{Fill Time Strategy}

1. I used the clock more than anything else. Over the experiments, I learned to look at the clock at the same time the liquid would hit the top of the tank without overfilling.

2. Watching the time on the clock was my strategy when it was an option; when the tank was full I would try to check the time before it began to overflow.

\section{Proportional Volume Strategy}

1. When the timer was not present, I tried to figure out what percentage of 6 the entire amount of liquid was. If the liquid overflowed, I would subtract that amount. If the liquid was not sufficient to overflow the tank, then I estimated the amount of liquid needed by using percentages and added that to the 6 .

2. The only strategy I used was estimating fractions. I looked at how much water was filled at 6 hours and I tried to estimate the fraction that was left unfilled. Then divide the hours among the fractions.

The report above also contains a distinction between using the clock to estimate time of overflow and using the clock to estimate the rate of fill (second sentence). If the clock helped estimate the rate of fill, it would provide an explanation of why the students did better on underfill problems when the clock was present. Ten participants reported that the clock helped them estimate the rate of fill, whereas 14 participants reported using the clock to judge when the tank had begun to overflow. Three participants reported having used the clock for both reasons (as in the example above), and 6 participants mentioned having used the clock without specifying how it had helped. The finding that the participants were approximately evenly divided in how they used the clock is consistent with the lack of a significant clock $\times$ fill interaction.

Eliminated participants. There was a total of 41 mean errors that exceeded the criterion of $3 \mathrm{~h}$ among the 13 eliminated participants. These included 29 cases on underfilled tanks and 13 cases on overfilled tanks. These eliminated cases are consistent with the ANOVA analysis in which the remaining 45 participants were significantly more accurate on overfilled tanks than on underfilled tanks. The partitioning is also consistent with the ANOVA analysis that showed that the clock significantly reduced the magnitude of error. The large errors included 17 cases in which the clock was present and 24 cases in which the clock was absent.

However, a discrepancy occurred for the overflow tank, because 27 of the 41 large errors occurred when the overflow tank was present. Although the overflow tank had a positive effect for the 45 participants included in the ANOVA, it had a detrimental effect for a few participants. Two of the eliminated participants had low error magnitudes on each of the four cases in which the overflow tank was absent but high error magnitudes on the four cases in which the overflow tank was present. Another participant had high error magnitudes for three cases, all occurring when the overflow tank was present. The effects of fill and the clock were, therefore, more consistent across participants than the effect of the overflow tank.

Component tasks. Another approach for investigating strategies is to determine how ability to perform component skills correlates with estimating event completion time. The proportional volume strategy requires accuracy in estimating volume and accuracy in proportional reasoning. The temporal extrapolation and fill time strategies require accuracy in comparing time on the clock with changing volume in the tank. Correlations between the ability to perform these component tasks and success in estimating completion time should provide additional evidence for strategy use.

The first component task required the students to judge the amount of liquid in the tank, including the overflow tank when there was an overflow. The amounts ranged from 0.5 to 1.5 tanks. Average error was determined by taking the absolute value of the difference between the estimated and the correct amounts. The participants whose average error was greater than 0.30 tanks were excluded from this analysis. The remaining 44 participants had a mean error of 0.05 tanks for the underfilled tanks and 0.04 tanks for the overfilled tanks. This difference was not significant $[t(43)=0.87, p>.05]$. These findings indicate that most of the students were fairly accurate in judging the proportion of the $\operatorname{tank}(\mathrm{s})$ that was filled for both underfilled and overfilled tanks.

In the second component task, we investigated arithmetic skills by requiring the estimation of completion time for verbally stated problems that had the same content as the animated problems. We used the same rule for excluding data that we used for the animated problems. Seven participants had an error of at least $3 \mathrm{~h}$ in at least one of the eight conditions and were excluded. The average error of the remaining 51 participants was $0.80 \mathrm{~h}$ for the underfilled tanks and $0.58 \mathrm{~h}$ for the overfilled tanks $[t(51)=$ $2.54, S E=.09, p<.02]$. The magnitude of error was similar to that found for the animation problems.

The third component task required the students to judge the time at which the tank was exactly full for each of the five overfilled tanks. The fast (3-sec) simulations and the need to monitor both the clock and the tank made this a nontrivial task. The average error was $0.24 \mathrm{~h}$ after 3 students who had made errors greater than $0.50 \mathrm{~h}$ were excluded.

Our main interest in investigating performance on these component tasks was to measure how well the tasks correlated with the accuracy of estimated completion time. We computed Spearman rank order correlations so we could include our entire sample of 58 participants, including those with high error magnitudes. The correla- 
tions between mean error in estimating task completion time and the three component tasks were $.51(p<.001)$ for judging volume, $.35(p<.01)$ for judging time of overfill, and $.34(p<.01)$ for estimating completion time for the verbally stated problems.

\section{Discussion}

Our findings provide converging evidence that participants use both temporal and spatial information to estimate event completion time (although the verbal reports suggest individual differences in which source is emphasized). Both a temporal task (judging time of overflow) and a spatial task (judging volume) correlated at least as well as the verbal estimation task. These results are surprising, because we anticipated that the verbally stated problems would produce the highest correlation, since the content of these problems was identical to that of the simulated problems.

The high correlations with the perceptual tasks support those theorists who have argued for the importance of perceptual components in skill acquisition. For example, Ackerman and Cianciolo (2000) showed the importance of perceptual predictors in their investigation of cognitive, perceptual speed, and psychomotor determinants of individual differences in acquired skill. They concluded that applied psychology in the last 40 years had overemphasized the role of general intelligence and underemphasized the roles of perceptual speed and psychomotor determinants in acquiring skill. One likely important component in estimating completion time is the updating and monitoring of information-one of three executive skills reported by Miyake, Friedman, Emerson, Witzki, and Howerter (2000). Monitoring and updating information is needed both for monitoring time on the digital clock and for monitoring the rise of liquid in a tank.

Other results that support the use of both temporal and spatial information are that estimates were more accurate if either the clock or the overflow tank was included in the display. The clock provided useful temporal information, and the overflow tank (with a few exceptions) provided useful spatial information. The overflow tank supports the proportional volume strategy, and the clock supports the temporal extrapolation strategy on underfill problems and the fill time strategy on overfill problems. In addition, all three strategies were mentioned in the verbal reports.

In addition to the clock and the overflow tank, the third variable (fill) also had a significant effect on estimation accuracy. We predicted that the students would be more accurate on overfilled tanks because knowledge of the restricted range should improve estimates (Reed, 1999, pp. 177-180). The correct answers for the underfilled tanks ranged from 12 to $6 \mathrm{~h}$ and the correct answers for the overfill problems ranged from 6 to $4 \mathrm{~h}$. Our prediction was supported for both the visual animation problems and the verbal problems and suggests that the participants may have calculated and used the range to constrain their estimates. Support for this interpretation comes from the finding that 847 (94\%) of the students' 900 estimates on the underfill animation problems were between 6 and $12 \mathrm{~h}$ and $781(87 \%)$ of the students' 900 estimates on the overfill problems were between 4 and $6 \mathrm{~h}$. Furthermore, $96 \%$ of the estimates on the overfill problems were between 3 and $6 \mathrm{~h}$.

\section{EXPERIMENT 2}

Experiment 1 demonstrated that the participants used several different strategies, including a proportional volume strategy. The proportional volume strategy does not depend on animation of the event, because only the volume in the tank after the tank stops filling is used. Although this strategy works well when the rate of fill remains constant, it cannot be applied without adjustments if the fill rate changes. We distinguish between constant and variable fill rates in Experiment 2 to determine whether people (1) inappropriately use the perceptual volume strategy when there is a change in fill rate and (2) produce more accurate estimates when viewing an animation of the change.

Experiment 2, therefore, included two problem types that had a constant rate of fill and two problem types that had a variable rate of fill. The constant rate problems included no-leak problems similar to the types of problems used in Experiment 1 and bottom leak problems in which there was a constant loss of water as the tank filled. The variable rate problems included side leak problems in which the rate of fill slowed down above the leak and delay problems in which a single pipe began filling before a second pipe was added later. We tested the prediction in Experiment 2 that viewing animated events would be more helpful than viewing static events for problems in which there was a rate change.

We tested this prediction by comparing two versions of the problems-one based on animated displays and one based on static displays. The static display showed only the end state of the animation-the amount of water in the tank when the liquid stopped rising. Because some of the problems involved rate changes, this information would be useless without knowing whether and how the rate changed. Both animated and static displays were, therefore, accompanied by a verbal statement of the problem, unlike in Experiment 1, in which the verbally stated problem occurred only as one of the component tasks at the end of the experiment. Figure 2 shows the verbal statements and end states for the four different problems in one of the series.

Because the proportional volume strategy would produce faulty estimates if there were a rate change, we instructed the students to use a mental simulation strategy on the animated problems. If at the end of the animation, the student mentally simulated the tank's continuing to fill at its current rate until it reached the top, he or she could add the mental simulation time to the $6 \mathrm{~h}$ to estimate the completion time. This strategy corresponds to running a mental model (Norman, 1983) in which mental simulation continues the rate of fill when the animation stops. We instructed the participants to use the mental simulation strategy in Experiment 2, to determine whether it would be effective for rate changes. To determine the accuracy of their mental simulations, we instructed the students to 
press a response key when their mental simulation reached the top of the tank.

We used the results to evaluate three hypotheses. The first hypothesis was that estimates of event completion time would be more accurate for static displays than for animated displays when there was no rate change (no leak and bottom leak problems). Experiment 1 revealed that students could quite accurately judge proportional volume, and it was likely that judging total time on the basis of a mental simulation would be less accurate. For example, Norman $(1983$, p. 8) has suggested that people have limited ability to run their mental models.
A

One pipe can fill a 10-foot tank in 10 hours and another pipe can fill a tank in 15 hours. How long will it take to fill the tank?

B

One pipe can fill a 10-foot tank in 10 hours and another pipe can fill a tank in 15 hours. There is a leak in the bottom of the tank that empties $1 / 18$ th of the tank each hour. How long will it take to fill the tank?

C

One pipe can fill a 10-foot tank in 10 hours and another pipe can fill a tank in 15 hours. There is a leak 3 feet from the bottom of the tank that empties $1 / 18$ th of the tank each hour. How long will it take to fill the tank?

D

One pipe can fill a 10-foot tank in 10 hours and another pipe can fill a tank in 15 hours. How long will it take to fill the tank if the 15-hour pipe begins 3 hours after the 10-hour pipe?

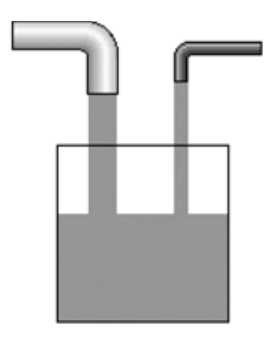

Time: 3.6 Hours
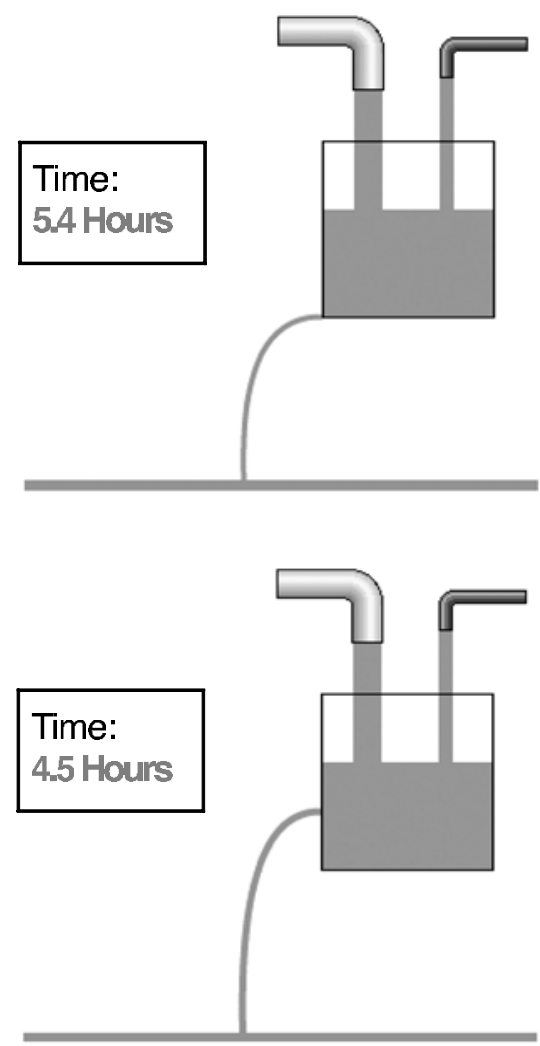

Time: 4.8 Hours

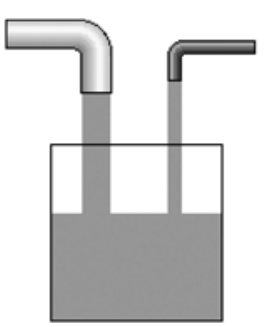

Figure 2. The (A) no-leak, (B) bottom leak, (C) side leak, and (D) delay problems from Series 3 in Table 4. 
Table 4

Parameters of Problems in Experiment 2

\begin{tabular}{ccccccc}
\hline Series & Stop $(\mathrm{ft})$ & Leak $(\mathrm{ft})$ & Pipe 1 (h) & Pipe 2 (h) & Delay $(\mathrm{h})$ & Loss $(\mathrm{h})$ \\
\hline 1 & 4 & 2.0 & 5 & 7 & 1 & 10 \\
2 & 5 & 2.5 & 8 & 12 & 2 & 16 \\
3 & 6 & 3.0 & 10 & 15 & 3 & 18 \\
4 & 7 & 4.0 & 5 & 9 & 2 & 12 \\
5 & 8 & 5.0 & 6 & 10 & 3 & 14 \\
\hline
\end{tabular}

Note:-Stop refers to the height of the liquid in the end state. Leak refers to location of the side leak from the bottom of a 10-ft tank. Pipe 1 and Pipe 2 show fill times, and Delay shows delay of Pipe 2. Loss shows loss rate. Each series consists of a no-leak, a bottom leak, a side leak, and a delay problem, as is shown in Table 5.

The second hypothesis was that estimates of event completion time would be more accurate for animated displays than for static displays when there was a rate change (side leak and delay problems). As was discussed previously, the proportional volume strategy does not provide accurate estimates in this case and will systematically bias the estimates. Previous research has shown that students often use proportional reasoning indiscriminately, such as in the following problem, which is accompanied by a picture of a tapered flask:

A flask is being filled from a tap at a constant rate. If the depth of the water is $2.4 \mathrm{~cm}$ after $10 \mathrm{sec}$, about how deep will it be after $30 \mathrm{sec}$ ?

Students often give unrealistic answers to these problems by using proportional reasoning when it does not apply (Verschaffel, Greer, \& De Corte, 2000). The animated displays may help prevent this indiscriminate use of proportional reasoning.

The final hypothesis concerned individual differences. We predicted that students who produced more accurate mental simulations of event completion would produce more accurate estimates of event completion time for the animated displays, as revealed by a significant correlation between the accuracy of the mental simulations and the accuracy of estimated completion time.

\section{Method}

Participants. The participants were 55 students at San Diego State University. They received extra credit in an introductory psychology course for participating. They were tested in small groups in a large computer classroom.

Stimuli. Table 4 shows the parameters used to construct the 20 test problems, which were identical for both displays. Each row in Table 4 shows a series representing a no-leak, a bottom leak, a side leak, and a delay problem. The following constraints were applied in constructing the problems in each series: (1) the fill rate of each pipe remained the same across problems; (2) the loss rate was the same for the bottom leak and the side leak; (3) the loss rate was slightly less than the fill rate of the second pipe; (4) the height of the end state was identical across problems; and (5) the height of the rate change was identical for the side leak and the delay problems.

Each display consisted of a verbal description of the problem at the top of the screen and a diagram below the problem. The diagram consisted of the tank and the digital clock. There was no overflow tank, because there were no overflow problems. The clock showed the time to partially fill the tank. The problem statements, partial fill times, and tanks for the four problems in Series 3 in Table 4 are shown in Figure 2.
Procedure. The students were randomly assigned to one of two orders distinguished by whether the animated displays or the static displays occurred first. For both the static and the animated conditions, they saw a no-leak, a bottom leak, a side leak, and a delay practice problem before receiving the 20 test problems. They received the 20 test problems in a random order that differed across participants. There was no feedback regarding correct answers on any of the (practice and test) problems.

The instructions for the static display were the following:

This part of the task requires that you combine information in the problem statement with information in a static display to estimate how long it will take to fill the tank. The visual display includes a clock that shows how long it took to fill part of the tank.

First, read the problem statement. Second, look at the clock and the partially filled tank to see how much of the tank filled for the time shown on the clock. Then combine the information in the problem statement and in the visual display to estimate how long it would take to fill the entire tank.

We will first show you a practice problem for each of the four problem variations (no leak, bottom leak, side leak, delay). We will then show you the 20 test problems. Remember that these are estimation problems, not calculation problems, so you should not use paper or a calculator to try to solve the problem. If you have any questions about the task, ask the experimenter as you work on the practice problems.

In contrast, the instructions for the animated display encouraged use of the mental simulation strategy. The instructions were the following:

Table 5

Estimated Completion Times (in Hours) and Error Across Problems

\begin{tabular}{|c|c|c|c|c|c|c|}
\hline \multirow[b]{2}{*}{ Series } & \multirow[b]{2}{*}{ Problem } & \multirow[b]{2}{*}{ Correct } & \multicolumn{2}{|c|}{ Animate } & \multicolumn{2}{|c|}{ Static } \\
\hline & & & Time & Error & Time & Error \\
\hline \multirow[t]{4}{*}{1} & no leak & 2.9 & 3.19 & 0.73 & 3.39 & 0.74 \\
\hline & bottom & 4.1 & 4.03 & 1.06 & 4.03 & 0.90 \\
\hline & side & 3.9 & 3.79 & 0.77 & 4.24 & 0.89 \\
\hline & delay & 3.3 & 3.44 & 0.81 & 3.87 & 0.96 \\
\hline \multirow[t]{4}{*}{2} & no leak & 4.8 & 4.35 & 0.77 & 4.79 & 0.77 \\
\hline & bottom & 6.9 & 5.93 & 1.32 & 6.28 & 1.21 \\
\hline & side & 6.3 & 5.28 & 1.57 & 5.73 & 1.16 \\
\hline & delay & 5.6 & 5.38 & 1.13 & 5.78 & 1.18 \\
\hline \multirow[t]{4}{*}{3} & no leak & 6.0 & 4.95 & 1.37 & 5.53 & 1.24 \\
\hline & bottom & 9.0 & 7.11 & 2.16 & 8.10 & 2.00 \\
\hline & side & 8.1 & 6.60 & 1.71 & 6.98 & 2.07 \\
\hline & delay & 7.2 & 6.13 & 1.46 & 6.82 & 1.67 \\
\hline \multirow[t]{4}{*}{4} & no leak & 3.2 & 2.95 & 0.57 & 3.18 & 0.68 \\
\hline & bottom & 4.4 & 3.97 & 0.81 & 4.37 & 0.95 \\
\hline & side & 3.9 & 3.27 & 0.94 & 3.89 & 0.92 \\
\hline & delay & 3.9 & 3.76 & 0.74 & 4.10 & 0.75 \\
\hline \multirow[t]{4}{*}{5} & no leak & 3.8 & 3.29 & 0.67 & 3.42 & 0.64 \\
\hline & bottom & 5.1 & 4.54 & 0.69 & 4.87 & 0.82 \\
\hline & side & 4.4 & 4.06 & 0.80 & 4.16 & 0.69 \\
\hline & delay & 4.9 & 4.69 & 0.72 & 4.74 & 0.63 \\
\hline
\end{tabular}


Table 6

Estimation Errors (in Hours) Across the Four Problem Types

\begin{tabular}{|c|c|c|c|c|c|c|c|c|}
\hline \multirow[b]{2}{*}{ Condition } & \multicolumn{2}{|c|}{ No Leak } & \multicolumn{2}{|c|}{ Bottom Leak } & \multicolumn{2}{|c|}{$\underline{\text { Side Leak }}$} & \multicolumn{2}{|c|}{ Delay } \\
\hline & $M$ & $S D$ & $M$ & $S D$ & $M$ & $S D$ & $M$ & $S D$ \\
\hline 10 & .81 & 0.81 & 1.17 & 1.05 & 1.15 & 0.99 & 1.04 & 0.9 \\
\hline Animate estimate & 0.82 & 0.63 & 1.21 & 0.83 & 1.16 & 0.74 & 0.97 & 0.87 \\
\hline Simulation time & 1.58 & 1.31 & 1.73 & 1.31 & 1.93 & 1.68 & 1.56 & 1.21 \\
\hline
\end{tabular}

This part of the task requires that you combine computer animation with your own mental animation to estimate how long it will take to fill the tank. The computer animation will show a tank filling as a clock records the time. The tank will then suddenly stop filling and the clock will also stop. At this point, imagine the water continue to fill at the same rate until it reaches the top of the tank. The specif ic instructions for this task follow.

First, read the problem statement. Second, place your index finger on the space bar. Third, press the space bar to begin the animation. Fourth, visually track the water filling the tank. Fifth, when the animation stops, imagine the water continuing to fill the tank at the same rate as when the animation stopped. Sixth, when your mental animation reaches the top of the tank, press the space bar again so we can time the accuracy of your mental animation. And finally, provide an estimate of how long it took to fill the tank.

The time on the clock shows how much time it took to partially fill the tank during the computer animation. You should then estimate the total time to fill the tank based on how much longer it took to fill the tank using mental animation. For example, if the clock shows that it took 4 hours to fill the tank during the computer animation and your mental animation took half as long as the computer animation, then you should estimate that it would take 6 hours to fill the entire tank (4 hours + 2 hours).

At the end of the experiment, the students were asked about their use of two strategies. For the static condition, the two strategies were using the proportion of liquid in the tank (as displayed in the diagram) or using the numbers in the written statement of the problem. The students indicated the relative importance of the two strategies by clicking on one of seven radio buttons that were labeled diagram at the left end and problem at the right end. The students rated their strategy use for each of the four problems so we could evaluate whether they would place less emphasis on the proportion of liquid in the tank (diagram) for the two problems in which there was a rate change. They then made the same judgments for the animate condition, in which the two strategies were use of the diagram and use of mental simulation. We again were interested in learning whether the students would place less emphasis on proportion of liquid in the tank when there was a rate change.

\section{Results}

Estimated completion time. Table 5 shows the correct answer, mean estimated answer, and mean error for each of the 20 problems used in the animate and static conditions. The means were based on all the data, except for two entries that appeared to be typing errors (55 and 209) and four missing entries that followed faulty displays. These data reveal a greater tendency to underestimate completion time in the animate condition, perhaps because of representational momentum (Freyd, 1987) that would cause the participants to begin their mental simulation above the point at which the physical rise of the water stops. However, there is little difference in error across the two conditions, defined as the absolute difference between the correct and the estimated answers.

The first two rows in Table 6 show the mean and standard deviation of the error for each of the four problem types. A 2 (condition: animate or static) $\times 4$ (problem: no leak, bottom leak, side leak, or delay) ANOVA revealed that there was no difference between the animate and the static conditions in error magnitude $\left[F(1,54)<1, M S_{\mathrm{e}}=\right.$ $0.77]$. However, there was a significant difference in estimation error across problems $\left[F(3,162)=15.91, M S_{\mathrm{e}}=\right.$ $0.20, p<.001]$.

More important, the hypothesized condition $\times$ problem interaction was not significant $\left[F(3,162)<1, M S_{\mathrm{e}}=\right.$ $0.15]$. We predicted that the students would do better on the no-leak and bottom leak problems in the static condition and would do better on the side leak and delay problems in the animate condition. Instead, the error magnitudes were virtually identical for the two conditions across problems. We will discuss the implications of this finding after reporting the simulation and strategy data, since both are relevant for analyzing our unsuccessful prediction.

Although we did not make any predictions regarding the sequential order of the presentations, we did find a significant order $\times$ problem interaction $[F(3,159)=2.96$, $\left.M S_{\mathrm{e}}=0.20, p=.034\right]$. Error magnitudes were lower for those students who viewed the animated displays before the static displays, but the amount of reduction depended on the problem. Viewing the animated displays first reduced the error magnitudes from 1.38 to $1.01 \mathrm{~h}$ for the side leak, from 1.23 to $1.08 \mathrm{~h}$ for the bottom leak, from 0.87 to $0.76 \mathrm{~h}$ for no leak, and from 1.01 to $1.00 \mathrm{~h}$ for the delay problem. These data indicate that the students benefited from initially seeing animations of some of the events and that this experience transferred to the judgment of static events.

Simulated completion time. We analyzed the accuracy of the mental simulations by converting the total (animated plus simulated) time in seconds to fill time in hours by using the conversion (animation) rate of $2 \mathrm{~h}$ per sec. We then defined simulation error as the absolute difference between simulated time and correct time, to give us a measure that was comparable to estimation error. We rejected as outliers simulation errors greater than $10 \mathrm{~h}$ (which may have been caused by distractions or forgetting to press the space bar), which occurred for 46 of the 1,100 simulation times. We used the remaining data to calculate a mean simulation error for each participant for the four problem types.

The third row in Table 6 shows the means and standard deviations of these mean simulation errors. As was found for estimation of completion time, there was a significant effect of problem type $\left[F(1,54)=4.00, M S_{\mathrm{e}}=0.41, p<\right.$ $.01]$. The finding that both the estimation and simulation errors were larger for the bottom and side leak problems suggests that the mental simulations may have influenced the estimates of event completion time. However, the finding that the estimation errors were also larger for the leak problems in the static condition (perhaps because of the more demanding arithmetic calculations) weakens this interpretation. Another difficulty with the interpretation of a causal relation between simulation and estimation is that even with the rejection of the largest simulation errors, the mean simulation errors were still substantially larger than 
the mean estimation errors in the animated condition. This finding suggests that the participants were basing their estimates of completion time on additional information, rather than solely on simulation time.

The use of additional information is supported by the failure of the data to support the hypothesis that there would be a significant correlation between the accuracy of the simulations and the accuracy of estimated completion time. The Spearman rank order correlation between simulation accuracy and estimation accuracy was .03 for the no-leak problems, -.26 for the bottom leak problems, -.29 for the side leak problems, and -.07 for the delay problems. Clearly, the students used information other than simulation time to estimate event completion time.

Reported strategies. An obvious candidate for other information is the written statement of the problem. One might even argue that the near identity of estimation error across the animate and static conditions occurred because the students focused entirely on the written problem and ignored the information in the display. However, as is shown in Table 7, this explanation is not supported by the students' ratings of the relative importance of the display and the written problem. This is seen most dramatically for the static displays of the no-leak and bottom leak problems. There were a total of 55 responses (out of 110) that checked the button closest to the diagram end of the continuum, suggesting that the students relied almost entirely on the display for these problems. In contrast, this total declined to 29 for the side leak and delay problems, indicating many of the students realized that it was inappropriate to rely only on the display when there was a rate change.

There are corresponding shifts for the animated problems for which the students had to indicate their relative use of a spatial (diagram) versus a temporal (mental simulation) strategy. The total number of responses that indicated complete reliance on the diagram declined from 32 for the no-leak and bottom leak problems to 11 for the side leak and delay problems. These data indicate that many of the students relied on the proportion of liquid in the tank instead of, or in addition to, simulation time, which could account for the low correlations between simulation error and estimation error. However, as was the case for the sta-

Table 7

Rated Strategy Use for the Static and Animate Conditions

\begin{tabular}{|c|c|c|c|c|c|c|c|}
\hline Static & \multicolumn{5}{|c|}{ (Diagram) } & \multicolumn{2}{|c|}{ (Problem) } \\
\hline No leak & 33 & 4 & 3 & 6 & 3 & 2 & 4 \\
\hline Bottom leak & 22 & 8 & 8 & 8 & 4 & 4 & 1 \\
\hline Side leak & 14 & 7 & 14 & 9 & 4 & 5 & 2 \\
\hline Delay & 15 & 8 & 6 & 11 & 5 & 5 & 5 \\
\hline Animate & \multicolumn{5}{|c|}{ (Diagram) } & \multicolumn{2}{|c|}{ (Simulation) } \\
\hline No leak & 18 & 4 & 4 & 10 & 6 & 8 & 3 \\
\hline Bottom leak & 14 & 4 & 8 & 8 & 7 & 8 & 4 \\
\hline Side leak & 6 & 7 & 9 & 11 & 8 & 8 & 4 \\
\hline Delay & 5 & 4 & 8 & 13 & 10 & 7 & 6 \\
\hline
\end{tabular}

Note-The data entries represent the relative use of the diagram and problem in the static condition and the diagram and simulation in the animate condition. The seven radio buttons were anchored by Diagram on the left and either Problem or Simulation on the right. tic condition, they relied less on the end state diagram when there was a rate change.

\section{Discussion}

Two assumptions influenced our prediction that the students would be more accurate in the animate condition for the side leak and delay problems. The first assumption was that the students would inappropriately rely on the proportionalvolumestrategy when there were rate changes. The second assumption was that the students' mental simulations would be accurate enough to give the mental simulation strategy an advantage when there were rate changes. On the basis of our findings, both of these assumptions proved questionable.

Several aspects of our results show that the students appropriately adjusted their estimates in the static condition if there was a rate change. A reliance on the proportional volume strategy would underestimate event completion time in the side leak problem, because the leak would decrease the fill rate. Similarly, using volume would overestimate event completion time in the delay problem, because of the increase in fill rate. Table 5 shows that this pattern occurred for only one (Series 3 ) of the five series. The strategy data in Table 7 also show that the students appropriately paid more attention to the numbers in the problem and less attention to the volume in the tank for problems that had a rate change.

These findings are encouraging when placed in the context of previous findings that have shown that students typically applied proportional reasoning inappropriately to such problems as An athlete's best time to run a mile is 4 min and $7 \mathrm{sec}$. About how long will it take him to run 3 miles? (Greer, 1993) Although Greer tested 13- and 14year-olds, Verschaffel, De Corte, and Borghart (1996) found that more than half of the answers given by 332 preservice teachers involved proportional reasoning when proportional reasoning was inappropriate.

Our assumption about students' ability to mentally simulate fill rate was also challenged by our data. As is indicated in Table 6, the students' simulation errors were greater than their estimation errors. This is consistent with Norman's (1983) observation that people's ability to "run" their mental models is severely limited. However, there have been success stories in using mental simulation, such as judging how far one can tilt a partially filled container before it spills, a judgment that was greatly aided by mentally simulating the tilt of the glass (Schwartz \& Black, 1999). Previous research demonstrating an extremely high correlation between distance and mental scan time (Kosslyn, Ball, \& Reiser, 1978; Reed, Hock, \& Lockhead, 1983) made us optimistic that students could accurately simulate fill rate. A difference, however, is that in the current task they had to simulate different rates by continuing an animation. A more closely related task is one cited by Call (2000), in which monkeys could predict the location of a moving target after it had passed behind a screen.

With the advantage of hindsight based on our findings and an additional task analysis, we now believe that we 
were misguided in instructing the students to use the mental simulation strategy. One challenge is that an extremely high level of calibration is required for an accurate mental simulation based on an animation rate of $2 \mathrm{~h}$ per sec. Part of this challenge is to adjust to rate changes when they occur. As has been discussed by Tversky, Morrison, and Betrancourt (2002), animations may be too complex or too fast to be accurately perceived. Another challenge is that after performing a mental simulation, the participants had to estimate how long their mental simulation took. The previously cited mental simulation tasks recorded simulation times but did not require the participants to estimate time. Accurate estimates of simulation time may be extremely difficult for people (Dan Schwartz, personal communication, February 17, 2002), particularly at the level of precision required in our task.

The lack of correlation between estimation accuracy and simulation accuracy in our results indicates that the participants used other information besides mental simulation times to make their estimates. It is likely that they relied on the written problem statement in the animated condition, as they did in the static condition. They may have also used the temporal extrapolation strategy by using flow rate when the animation stopped, to estimate how long it would take to fill the remainder of the tank.

\section{GENERAL DISCUSSION}

\section{Theoretical Implications}

Hecht's (2000) emphasis on situational and personal variables for event perception provided a context for this research. The data support the use of all three of our proposed strategies in Experiment 1-the proportional volume strategy, the temporal extrapolation strategy, and the fill time strategy. The role of situational variables is demonstrated by the influence of temporal (clock) and spatial (overflow tank) aids to improve the calibration of space and time. The influence of personal variables is illustrated by individual differences in reported strategy use. Some students reported using only one of the three strategies, whereas other students used multiple strategies that depended on the availability of the visual aids.

We were surprised to find that the perceptual tasks, judging volume and fill time, correlated more consistently with estimation accuracy than did the arithmetic task. Although experts (nurses who mentally calculate appropriate doses of drugs) are good at doing proportional reasoning (Hoyles, Noss, \& Pozzi, 2001), we anticipated that the arithmetic task would limit novices' accuracy in estimating completion time. However, the higher correlations for the two perceptual tasks support the arguments of those who believe there is a strong perceptual component to many reasoning tasks (Ackerman \& Cianciolo, 2000; Barsalou, 1999; Fincher-Kiefer, 2001; Lohman, 1996).

An encouraging aspect of our findings is that most of the students in Experiment 2 showed good judgment in how they used the three information sources (problem statement, static diagram, and animated diagram) to pro- duce fairly accurate estimates of event completion time. First, the students made adjustments by relying less on the static diagram and more on the problem text or the animation when the proportional volume strategy was inappropriate. As a result, they did not underestimate completion times in the side leak problems or overestimate completion times in the delay problems. Second, the students did not rely extensively on their faulty mental simulation times to produce estimates of event completion time. These data are supportive of the framework proposed by Brown and Siegler (1993), in which people use multiple cues to derive an estimate and weight each cue according to its predictive accuracy relative to alternative cues.

\section{Instructional Implications}

Although there has been much research and theoretical development regarding the use of static images, the relative lack of research on dynamic images poses a challenge for the principled design of instructional animation (Rieber \& Kini, 1991). Subsequent research has identified task variables that influence when animation is effective (Kaiser, Proffitt, Whelan, \& Hecht, 1992), but there is still insufficient knowledge to guide the design of instructional animation in most situations.

We are currently designing a series of Animation Tutor modules in which instructional animation is used to improve students' reasoning, estimation, and problem-solving skills in an intermediate algebra class. The purpose of the second module in the series is to improve students' ability to estimate, and then calculate, answers to the four types of tank-filling problems studied in Experiment 2. Visual feedback from the animation of the estimated completion time has been effective in significantly improving estimates (Reed, Cooke, \& Jazo, 2002). However, we had no idea what strategies students had used to do this, so we investigated strategy use in this study.

Our finding that both the clock and the overflow tank improved estimates in Experiment 1 justifies our decision to include both visual aids in the Animation Tutor: Task Completion module. One reason for including both aids is that those students who use a temporal strategy and those students who use a spatial strategy have an aid for improving calibration. An advantage of providing for multiple representations is that students have different preferences for which representation they find most helpful. For example, when asked which representation in the Animation Tutor: Average Speed module they found most helpful for understanding why the average speed cannot exceed twice the slower speed, 10 students selected the algebraic approach, 8 students selected the conceptual approach, and 6 students selected the graphic approach (Reed \& Jazo, 2002).

A central issue in designing instructional animation is determining when animation is effective (Narayanan \& Hegarty, 2002; Tversky et al., 2002). The finding that the clock significantly improved estimates in Experiment 1 and the reported use of the temporal extrapolation and fill 
time strategies indicates that animation was helpful for at least some of the students. A nonsupportivefinding in Experiment 2 was the failure to find any difference in the accuracy of the estimates for the static and the animated displays. This may have been caused by our instructions to use a (mental simulation) strategy that was difficult to implement. The finding that the students reported placing greater emphasis on animation for the rate change problems in Experiment 2 suggests a reliance on animation when the proportional volume strategy is inappropriate.

Learning how to design more effective instructional animation will depend on learning how students use spatial and temporal information to improve their reasoning about events. Our experiments have given us the opportunity to consider a variety of cognitive processes, such as mental calculation, effect of range in constraining estimates, mental simulation, use of space (volume) and time in making judgments, analog-to-digital conversion, and task strategies. However, this study illustrates that there are many unanswered questions, and additional research is needed to provide an empirical and theoretical foundation for designing effective instructional animation and for learning more about event perception.

\section{REFERENCES}

Ackerman, P. L., \& Cianciolo, A. T. (2000). Cognitive, perceptualspeed, and psychomotor determinants of individual differences during skill acquisition. Journal of Experimental Psychology: Applied, 6, 259-290.

Barsalou, L. W. (1999). Perceptual symbol systems. Behavioral \& Brain Sciences, 22, 577-660.

Brown, N. R., \& Siegler, R. S. (1993). Metrics and mappings: A framework for understanding real-world quantitative estimation. Psychological Review, 100, 511-534.

CALL, J. (2000). Representing space and objects in monkeys and apes. Cognitive Science, 24, 397-422.

Dixon, J. A., \& MoOre, C. F. (1996). The developmental role of intuitive principles in choosing mathematical strategies. Developmental Psychology, 32, 241-253.

FINCHER-KIEFER, R. (2001). Perceptual components of situation models. Memory \& Cognition, 29, 336-343.

FRE YD, J. J. (1987). Dynamic mental representations. Psychological Review, 94, 427-438.

Greer, B. (1993). The mathematical modeling perspective on wor(1)d problems. Journal of Mathematical Behavior, 12, 239-250.

HECHT, H. (2000). The failings of three event perception theories. Journal for the Theory of Social Behavior, 30, 1-25.

Hoyles, C., Noss, R., \& PozzI, S. (2001). Proportional reasoning in nursing practice. Journal for Research in Mathematics Education, 32, 4-27.

Kaiser, M. K., Proffitt, D. R., Whelan, S. M., \& Hecht, H. (1992).
Influence of animation on dynamical judgments. Journal of Experimental Psychology: Human Perception \& Performance, 18, 669-690.

KIERAS, D. E., \& MEYER, D. E. (2000). The role of cognitive task analysis in the application of predictive models of human performance. In J. M. Schraagen, S. F. Chipman, \& V. L. Shalin (Eds.), Cognitive task analysis (pp. 237-260). Mahwah, NJ: Erlbaum.

KosSLYn, S. M., BALl, T. M., \& REISER, B. J. (1978). Visual images preserve metric spatial information: Evidence from studies of visual scanning. Journal of Experimental Psychology: Human Perception \& Performance, 4, 47-60.

Lohman, D. F. (1996). Spatial ability and g. In I. Dennis \& P. Tapsfield (Eds.), Human abilities: Their nature and measurement (pp. 97-116). Mahwah, NJ: Erlbaum.

Miyake, A., Friedman, M. P., Emerson, M. J., Witzki, A. H., \& HowERTER, A. (2000). The unity and diversity of executive functions and their contributions to complex "frontal lobe" tasks: A latent variable analysis. Cognitive Psychology, 41, 49-100.

Narayanan, N. H., \& Hegarty, M. (2002). Multimedia design of communication of dynamic information. International Journal of Human-Computer Studies, 57, 279-315.

Norman, D. A. (1983). Some observations on mental models. In D. Gentner \& A. L. Stevens (Eds.), Mental models (pp. 7-14). Hillsdale, NJ: Erlbaum.

REED, S. K. (1999). Word problems: Research and curriculum reform. Mahwah, NJ: Erlbaum.

REED, S. K., COOKE, J., \& JAZO, L. (2002). Building complex solutions from simple solutions in the Animation Tutor: Task completion. Mathematical Thinking \& Learning, 4, 315-336.

ReED, S. K., \& Evans, A. C. (1987). Learning functional relations: A theoretical and instructional analysis. Journal of Experimental Psychology: General, 116, 106-118.

ReEd, S. K., Hock, H. S., \& LockHeAd, G. R. (1983). Tacit knowledge and the effect of pattern configuration on mental scanning. Memory \& Cognition, 11, 137-143.

REED, S. K., \& JAZO, L. (2002). Using multiple representations to improve conceptions of average speed. Journal of Educational Computing Research, 27, 147-166.

Rieber, L. P., \& KINI, A. S. (1991). Theoretical foundations of instructional applications of computer-generated animated visuals. Journal of Computer-Based Instruction, 18, 83-88.

SCHWARTZ, D. L., \& BLACK, T. (1999). Inferences through imagined actions: Knowing by simulated doing. Journal of Experimental Psychology: Learning, Memory, \& Cognition, 25, 116-136.

Tversky, B., Morrison, J. B., \& Betrancourt, M. (2002). Animation: Can it facilitate? International Journal of Human-Computer Studies, 57, 1-16.

Verschaffel, L., De Corte, E., \& Borghart, I. (1996, July). Preservice teachers' conceptions and beliefs about the role of real-world knowledge in arithmetic word problem solving. Paper presented at the 20th Conference of the International Group for the Psychology of Mathematics Education, Valencia, Spain.

Verschaffel, L., Greer, B., \& De Corte, E. (Eds.) (2000). Making sense of word problems. Heereweg, The Netherlands: Swets \& Zeitlinger.

(Manuscript received June 11, 2001; revision accepted for publication August 20, 2003.) 